\title{
IRISH RUGBY INJURY SURVEY: DUNGANNON FOOTBALL CLUB (1986-87)
}

\author{
K. ADDLEY* and J. FARREN** \\ *General Practitioner and * Research Biologist, Moy, Northern Ireland
}

\section{ABSTRACT}

The injuries sustained during one season by players at an Ulster Senior Rugby Club were documented with reference to time of injury, phase of play, team position, and nature of injury. The overall injury pattern in Irish rugby as found in this study is broadly comparable with that in similar studies in England and Scotland. Eighty-four players were injured in total. Three of these had fractures of which one required hospital admission for open reduction of a fractured wrist. The remaining eightyone players had various types and grades of soft-tissue damage. The tackle accounted for approximately one-third of all injuries. There were few serious injuries and none involving the spine. Injuries to forwards made up almost sixty per cent of the total.

Key words: Rugby, Injuries

\section{INTRODUCTION}

Although there have been studies concerning rugby injuries in schools in Ireland (IRFU, Dublin, 1984) there is no published data of a generalised nature relating to the game played at adult level. In this paper we have studied a senior club in the Ulster Branch of the Irish Rugby Football Union in an attempt to explore the problem.

Dungannon Football Club has five teams playing on a weekly basis drawn from a pool of approximately one hundred players. At present the 1st XV plays in section two of the Ulster Senior League. Over the past three seasons a medical rota has been in operation to provide cover for home games. Twelve doctors participate in this, assisted by the local St. John's Ambulance. The club has a treatment room with couch, orthoscoop stretcher, bandages and splints. There is also a club Physiotherapist.

Concern regarding the problem of rugby injury lead the IRFU to issue guidelines to clubs in relation to prevention, provision of equipment and facilities for treatment of injuries (IRFU, Dublin, 1983). As an adjunct to these guidelines we have attempted to provide baseline information which may be of interest to those involved in the game.

\section{METHODS}

The 1986-87 season, from September to April, was studied with respect to all home games played on Saturdays. An injury was taken to be the presence of pain, discomfort or disability arising during and as a result of playing in a rugby match. A questionnaire was used to record injury details. Injured players were interviewed immediately after the match and in order to eliminate observer bias the authors themselves completed each questionnaire. The following points were noted:-

1. Age

2. Time of injury

3. Phase of play

4. Team position

5. Nature of injury

The local accident and emergency department was

Address for correspondence:

Dr. K. Addley, MRCGP

The Health Centre

Charlemont Street

Moy

Co. Tyrone

N. Ireland contacted at a later stage to ascertain the treatment and final diagnosis of those referred.

\section{RESULTS}

During the eight month season forty matches were studied giving a total of 1200 player appearances. From this eightyfour injuries were documented representing an overall injury incidence of 1 per 14 appearances. Of this total twenty-one required first-aid treatment on the field of play with six of these being referred to hospital as possible fractures and three actually having sustained a fracture. The remaining sixty-three players required post-match treatment which included wound toilet, suturing, ice-pack application, strapping and referral for physiotherapy (Table I). The age range of injured players was between eighteen and forty-six years. The results are presented in the series of figures.

TABLE I

Wounds and Bruising

Lacerations (5) - wound toilet and suturing

Abrasions (6) - wound toilet and dressing

Bruising (20) - cold application

Ligament/Joint Sprains

Ankle (4) - strapping and general advice

Knee (3) - cold application, strapping and physiotherapy

Shoulder (2) - cold application and general advice

Wrist (1) - strapping and general advice

Muscle/Tendon Strains

Neck muscles (5) - general advice*

Deltoid (3) - general advice

Biceps (2) - general advice

Lumbar muscles (3) - cold application and general advice

Hamstring (5) - cold application and physiotherapy

Thigh (2) - cold application and general advice

Forearm (1) - general advice

Groin (1) - cold application and physiotherapy

\footnotetext{
* The term "general advice" was used on its own for injuries not requiring active treatment or as an addition to those where treatment was provided. It took the form of reassurance about the nature of the injury, the likely duration and some information as to how the player could influence the course of the injury himself if applicable.
}

Time at which injuries occurred (Fig. 1)

Forty-six per cent (39) of injuries occurred in the first half with fifty-four per cent (45) in the second. The second and 


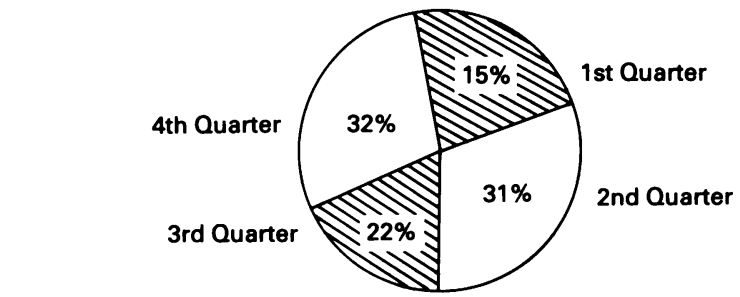

$100 \%=84$

Fig. 1: Time at which injuries occurred.

fourth quarter represent a total of sixty-three per cent between them compared with thirty-seven per cent for the combined first and third quarters. Thus the end of each half represents the most "at risk" time of the game.

\section{Phase of play/injury occurrence (Fig. 2)}

Injuries were correlated with the various phases of play which occur during a game. Eighty-seven per cent (73) were sustained in player to player contact whilst a much smaller number occurred in the non-body contact situation of running i.e. thirteen per cent.

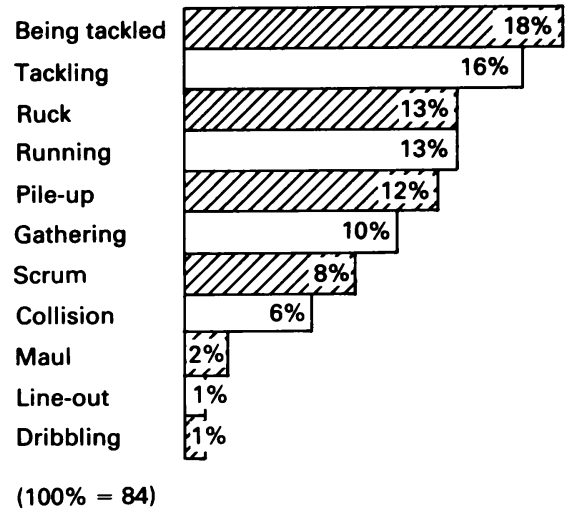

Fig. 2: Phase of play/injury occurrence.

\section{Position of player injured (Fig. 3)}

Injuries in the forwards accounted for a total of 60.5 per cent (51) in comparison with the backs with 39.5 per cent (33). The second row figure of twelve per cent is a combination of the two players who occupy this position on the team.

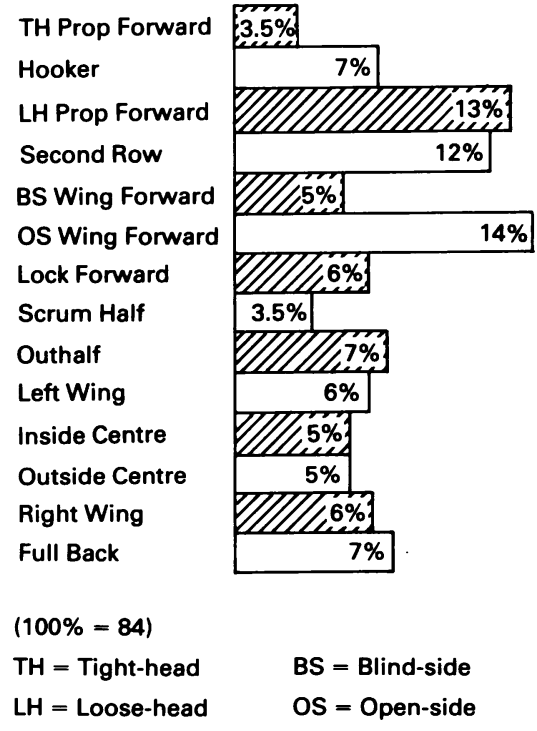

Fig. 3: Position of player injured.

\section{Anatomical site of injury (Fig. 4)}

Limb injuries accounted for sixty-three per cent (53) of the total. There were no serious neck injuries with all those recorded being soft-tissue in nature.

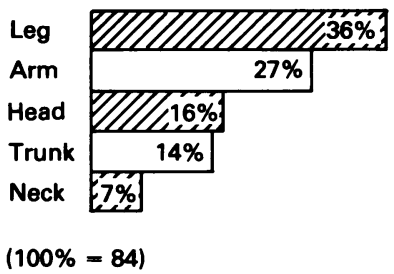

Fig. 4: Anatomical site of injury.

\section{Type of injury sustained (Fig. 5)}

Strains, sprains, bruising and wounds were collectively termed soft-tissue injuries and as such accounted for eighty-eight per cent (75) of the total. The joint dislocations were composed of Temporo-mandibular (1), Shoulder (1), and Acromioclavicular (1). Fractures consisted of Nasal bones (1), Metacarpal (1), and Smith's fracture of wrist (1).

Muscle/tendon Strain
Ligament/Joint Sprain
Bruising
Wounds
Joint Dislocation
Fracture
Concussion

Fig. 5: Type of injury sustained.

\section{DISCUSSION}

This type of study revealed difficulties relating to the voluntary reporting of injuries by players. Not all players were prepared to declare themselves injured and the level of co-operation seemed to be influenced by the performance of their team and the importance of the particular match. However it is reasonable to assume that these non-reported injuries would have been mostly softtissue in nature and so would not have unduly influenced the overall picture.

Although there was little difference between the first and second half in terms of numbers injured sub-division shows the second and fourth quarters to contain a larger proportion of the total injuries. This difference could perhaps be explained on the basis of tiredness or poor fitness leading to a greater susceptibility to injury. However it is not always possible to equate tiredness with lack of fitness and if reasonable fitness is defined as playing and training at least once a week then the vast majority of players in our study would be considered to be at least reasonably fit. Indeed in a study involving sports injuries presenting to an accident and emergency department at Edinburgh (Watters et al, 1984) it was shown that the vast majority of injuries occurred in reasonably fit individuals. Therefore, in general, fatigue induced by the pace of a game might be more causative of injury than lack of fitness on its own.

All phases of play have the potential to cause injury but some more than others. This is particularly so with the tackle and over one-third of all injuries resulted from this 
phase. A study of injuries by the Scottish RFU (SRU, Edinburgh, 1985) in 1984/85 found that six out of ten injuries resulted from the tackle and they concluded that the tackle is by far the most dangerous phase of the game. This confirms that players should be undertaking regular tackling practice in conjunction with the acquisition of falling skills to try and minimise the risks associated with this phase of play.

Second phase play in our study accounted for onequarter of injuries and highlights the importance of players joining rucks and mauls without causing injury to either themselves or others particularly those who have become trapped. Only a small number of injuries originated in the scrum despite the inherent danger of serious neck and back injuries in this phase of play. This could be a reflection of attention given by coaches (and referees) over recent years to good scrummaging skills and the outlawing of dangerous practices such as lowering, deliberate collapsing and power-impacting.

Non-contact injuries accounted for thirteen per cent of the total and these occurred during running. This might question the performance of adequate warming-up as well as the particular skills of turning and twisting quickly.

Forwards were injured more often than backs (approx. 60/40). This contrasts with a similar study based in Gloucester (Durkin, 1977) where injuries to backs predominated (55/45). It may be postulated that this difference reflects a contrast in style between the game in Ireland compared with England. This hypothesis is reinforced when the individual position of the player is examined. Top of the injury list in Dungannon is the wing forward followed by the prop in contrast to Gloucester where the fullback is followed by the centre three-quarter.

Limb injuries accounted for nearly two-thirds of all injuries and this would correlate with the tackle being the greatest causative event. Other injuries, especially those involving the neck, were few in number and not serious. Soft-tissue injuries formed the majority of those encountered $(88 \%)$ and these were made up of ligament injuries of the ankle and knee plus various other categories including hamstring pulls and intra-muscular haematomas. More serious injuries (fractures, joint dislocation and concussion) were fortunately few and did not account for any significant long term morbidity.

Provision of adequate first-aid cover for rugby matches would seem to be a reasonable minimal requirement in the light of the results of this survey. The availability of additional sophisticated back-up would be dictated firstly by the resources and enterprise of the individual club and secondly by more extensive study showing a need for such a provision.

\section{CONCLUSION}

This survey, whilst suggesting the incidence of serious injury to be low, highlights the lack of comprehensive data relating to rugby injury in Ireland. Further study involving a number of clubs throughout Ireland, perhaps co-ordinated by the IRFU, would lead to a more definitive documentation of the problem. Hopefully our initial endeavours would stimulate and encourage such a process.

\section{ACKNOWLEDGEMENTS}

Thanks are due to: Dr. B. McNamee, FRCP, Consultant Physician, South Tyrone Hospital; Mr. G. Spotswood, Game Development Officer IRFU; Mr. H. Graham, President Dungannon Football Club; Doctors on the club rota; Coaches, Captains and players of Dungannon FC; Patricia Watson for typing the manuscript.

\section{References}

Durkin, T. E., 1977 "A Survey of injuries in a 1st class Rugby Union Football Club from 1972-76". Brit.J.Sports Med. 11: 7-11.

Irish Rugby Football Union, 1984. Survey on neck injuries in schoolboy rugby Dublin.

Irish Rugby Football Union, 1983. Advice on prevention of injury/making rugby a safer game. Dublin.

Scottish Rugby Union, 1985. Significant injuries in rugby 1984-85. Edinburgh.

Watters, S. A., Brooks, S., Elton, R. A. and Little, K., 1984 "Sports Injuries in an accident and emergency department". Arch.Emerg.Med. 2: 105-11.
Title:

Author:

Publisher:

\title{
BOOK REVIEW
}

\section{THE RUNNING ATHLETE - ROENTGENOGRAMS AND REMEDIES}

\author{
Pavlov \& Torg
}

Y. B. Medical, Chicago. UK Agents Wolfe Medical, London 1987

Price: $£ 48.00 \quad 315$ pages with Index

ISBN 0815167121

This book is written by two well-known authorities in their fields, one a Radiologist, the other an Orthopaedic Surgeon. The book is basically a collection of radiographs and radioisotopic images of pathological abnormalities seen in the lower limb most commonly, although not always, due to sports injuries. It is divided into chapters, the foot, the ankle, the leg (tibia and fibula), the knee, the femur, the groin and the spine. After the radiograph and discussion of each individual abnormality a remedy is proposed. The scope of contents is suitable apart from the fact that it would have been nice to have more information about avulsion fractures around the ankle joint before arthrography is considered. The description of sesamoid fractures is theoretically nice but in practice without clinical information or follow-up films the diagnosis is often difficult. Myositis ossificans is an important consideration and could usefully have been given more space. The same applies to the occasional similarities of stress and avulsion fractures to bone tumours. The history is important in the differential diagnosis.

I think the remedies enclosed add nothing to the book, they give the idea of treating the radiograph and not the patient. It must be remembered that the book is really a radiological atlas and there is no clinical information given within it. The book is nicely produced, the radiographs are of good quality but some could have been more clearly labelled. The book is well worth a read and I think will be of use from time to time for help in studying an X-ray. It must however be remembered that radiographs cannot be used in diagnosis on their own, they must be considered alongside the patient's history and signs. 